\title{
Adsorption behavior of $\gamma$-aminopropyl trimethoxysilane on copper foil
}

\author{
Toshio Ogawa $\cdot$ Takuya Nobuta
}

Received: 2 June 2009/ Accepted: 28 October 2009/Published online: 11 November 2009

(C) The Author(s) 2009. This article is published with open access at Springerlink.com

\begin{abstract}
The adsorption behavior of $\gamma$-aminopropyl trimethoxysilane ( $\gamma$-APS) on copper foil is investigated by using X-ray photoelectron spectroscopy (XPS). Copper foil is immersed in a diluted aqueous solution of $\gamma$-APS and dried in air. It is found that $\gamma$-APS is adsorbed onto the surface almost without hydrolysis. Further, the depth profile by XPS analysis shows that $\gamma$-APS is not hydrolyzed even in the inside layer. In order to obtain hydrolyzed $\gamma$-APS on the copper foil surface, the foil is freeze-dried as immersed in a diluted aqueous solution of $\gamma$-APS. A hydrolyzed form of $\gamma$-APS is found on the top surface. Further, the presence of a powder is confirmed in the bottom of the flask at the end of the freeze-dry experiment. XPS analysis shows the powder is a linear polymer and produced from the silane coupling agent.
\end{abstract}

\section{Introduction}

Copper foil is widely used for preparing flexible print circuit (FPC). For example, FPC is always used in cellular phones and digital cameras. Copper foil is bonded with aromatic polyimide film during the production of FPC. However, this film is very hard and has relatively poor adhesive properties. So it is necessary to improve the adhesion between the copper substrate and the polyimide by using a coupling agent

\footnotetext{
T. Ogawa

Laboratory for Ecological Polymer Chemistry, Kanazawa

Institute of Technology, 7-1, Ohgigaoka, Nonoichi,

Ishikawa 921-8501, Japan

T. Nobuta $(\bowtie)$

Nitto Analytical Techno-Center Co., Ltd, 1-1-2, Shimohozumi,

Ibaraki, Osaka 567-8680, Japan

e-mail: takuya_nobuta@gg.nitto.co.jp
}

with a proper processing condition. This study is carried out by using a silane coupling agent in varying experimental conditions. Silane coupling agents are used for surface modification of not only fiberglass and metals, but also inorganic powders, polymers, and materials in all industrial areas. One advantage is that the surface is modified simply by immersing a material in an aqueous solution of a silane coupling agent and then drying it. Generally, a silane coupling agent is hydrolyzed in an aqueous solution and becomes silanol [1,2], which develops a dehydration reaction with hydroxyl groups on the material surface and forms $\mathrm{M}-\mathrm{O}-\mathrm{Si}$ bonds, where " $\mathrm{M}$ " is the target material. On the other hand, the adhesive strength of the materials is expected to be improved since the epoxy and amino groups at the tail ends of the silane coupling agent bind to the adherend. The adhesive strength in this case should be high, because covalent bond is formed in the both ends of the agent. It is observed that the silane coupling agent reacts with the hydroxyl group of the materials in the earlier stage of the drying process. In the next stage, silane coupling agent is deposited on the first layer. The chemical structure of the deposited silane coupling agent is very important to discuss adhesion problems. The coupling agent in solution polymerizes and forms oligomers [1,3] under specific conditions, followed by deposition on the first layer. Usually a distinction is made between the adsorption layer and the layer above it, where the former is known as the chemisorbed layer (first layer) and the latter is known as the physisorbed layer $[1,4]$. The type of developed layers depends on the experimental conditions [5, 6]. In the case of oligomers, most of the silanol would be consumed, and thus it cannot be expected that the silane coupling agent can contribute considerably to the adhesive strength. Generally the existence of physisorbed layer is not favorable for adhesion. Thus further the adhesion cannot be improved by the agent much as expected from the 
covalent bond formation or the above described mechanisms, suggesting that a lot of covalent bond have not been generated. That is why we reconsider this reaction mechanism for the silane coupling agent. More detailed studies are required for the deposited or adsorbed layers of $\gamma$-aminopropyl trimethoxysilane ( $\gamma$-APS) on the materials.

Transmission, diffuse reflection, and total reflection methods in infrared spectroscopy [7] are generally used for studying the behavior of silane coupling agents both in aqueous solutions and in the adsorption layer on a target material. Adsorption mechanisms were extensively studied in the 1980s. This paper reports on the mechanism of adsorption of $\gamma$-APS onto copper foil, which is studied in detail mainly by X-ray Photoelectron Spectroscopy (XPS) with a recently developed sputtering method using $C_{60}$ fullerene ions.

\section{Experiment}

Materials

The silane coupling agent KBM-903 $\gamma$-APS $\mathrm{NH}_{2}\left(\mathrm{CH}_{2}\right)_{3}$ $\mathrm{Si}\left(\mathrm{OCH}_{3}\right)_{3}$, Shin-Etsu Chemical Co., Ltd., Tokyo, Japan) is used without modification. The element ratio is $\mathrm{C}: \mathrm{N}: \mathrm{O}: \mathrm{Si}=$ 54.5:9.1:27.3:9.1 as determined by XPS. Electrolytic copper foil (Furukawa Electric Co. Ltd., Tokyo, Japan) with a thickness of $12 \mu \mathrm{m}$ is used. Although the details regarding the surface treatment by the manufacturer are not clear, the results of the XPS analysis will be discussed later.

Processing of copper foil with a silane coupling agent

An aqueous solution of the silane coupling agent is prepared using distilled water and is left for 1 day. Copper foil with dimensions of $2 \times 5 \mathrm{~cm}^{2}$ is immersed into the solution and hung, followed by drying it in air. The sample is then dried in vacuum with a rotary pump for $4 \mathrm{~h}$, after which an XPS analysis is performed. The concentration of the aqueous solution of silane coupling agent is usually $0.2 \mathrm{wt} \%$, and the immersion time of copper in the aqueous solution is $5 \mathrm{~min}$. The aqueous solution having the same concentration as described above, in which the copper foil is immersed, is frozen at $-40{ }^{\circ} \mathrm{C}$ and is dried using a freeze-dryer (FDUmodel 1200, Tokyo Rikakiki Co., Japan).

Surface analysis

XPS is a technique for quantitative spectroscopic determination of elemental composition. In this study an X-ray photoelectron spectrometer (ESCA-3400, Shimadzu Co., Japan, referred to as M-1 below) is used for surface analysis of the treated substrates. X-rays $(1253.6 \mathrm{eV})$ are generated with a $\mathrm{Mg}$ anti-cathode and an acceleration voltage of $8 \mathrm{kV}$ and a current of $30 \mathrm{~mA}$. The measurements are performed in vacuum below $10^{-6} \mathrm{~Pa}$. As is clear from the sample preparation and XPS analysis conditions, there are no molecules of the single silane coupling agent on the measurement surface.

For chemical composition analyses in vertical direction, we used an X-ray photoelectron spectrometer (PHI Quantera SXM, ULVAC-PHI, Inc. Japan, referred to as M-2), which allows for sputtering using $\mathrm{C}_{60}$ fullerene ions. $\mathrm{X}$-rays (1486.6 eV) are generated using an Al anti-cathode, and the measurements are conducted in vacuum below $10^{-7} \mathrm{~Pa}$. Sputtering is performed repeatedly in 1-min intervals. In order to estimate the sputtering speed [8], the sample is covered with a metal mesh, and following the sputtering, the sputtering depth is measured using a stylus profile meter, after which the depth can be calculated using the relation between the sputtering time and the depth.

\section{Results and discussions}

\section{Effects of processing conditions}

Although the details regarding the surface treatment of copper foil with metals are not clear, Fig. 1 indicates the presence of $\mathrm{Cr}, \mathrm{Ni}, \mathrm{Zn}$, and $\mathrm{Cu}$. Considering the adsorption of $\gamma$-APS, the elements on the surface of the copper foil related to the silane coupling agent have the ratio $\mathrm{C}: \mathrm{N}: \mathrm{O}: \mathrm{Si}=24.4: 0: 74.5: 1.0$, indicating the presence of a large amount of oxygen. Table 1 shows the effects of the immersion time on the amount of the silane coupling agent

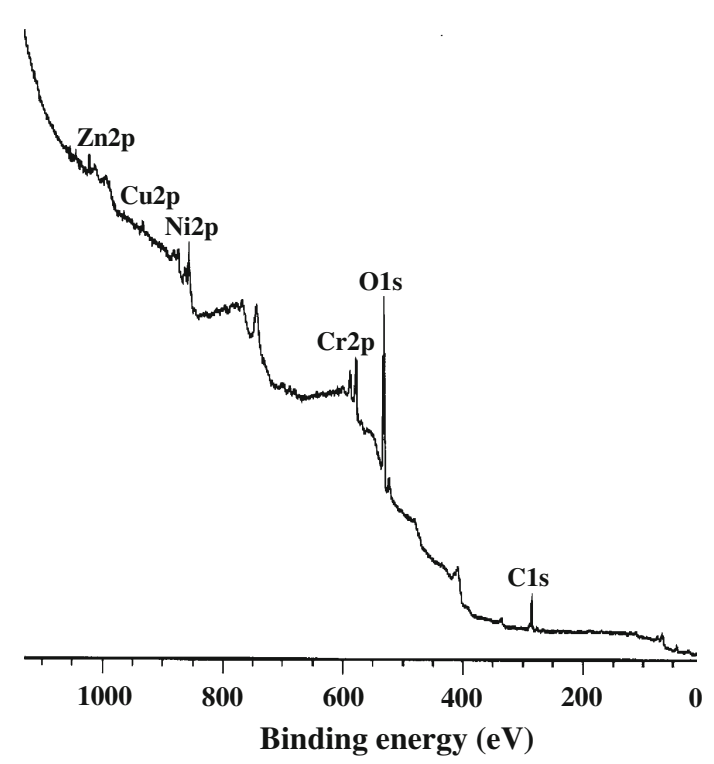

Fig. 1 XPS spectrum of copper foil (M-1) 
Table 1 Immersion time dependence on the amount of adsorbed $\gamma$-APS ${ }^{\mathrm{a}}$

\begin{tabular}{lllll}
\hline $\begin{array}{l}\text { Immersion } \\
\text { time (min) }\end{array}$ & \multicolumn{4}{l}{ Atomic concentration $(\%)$} \\
\cline { 2 - 5 } & $\mathrm{C}$ & $\mathrm{N}$ & $\mathrm{O}$ & $\mathrm{Si}$ \\
\hline 1 & 44.0 & 2.1 & 49.8 & 4.1 \\
5 & 58.9 & 7.3 & 25.2 & 8.6 \\
7 & 55.2 & 8.4 & 27.6 & 8.8 \\
\hline
\end{tabular}

${ }^{\mathrm{a}}$ Water solution of $\gamma$-APS at $1.0 \%$ by volume was used

Table 2 Effect of concentration on amount of adsorbed $\gamma$-APS

\begin{tabular}{lllll}
\hline $\begin{array}{l}\text { Concentration } \\
\text { of } \gamma \text {-APS }(\%)\end{array}$ & \multicolumn{5}{l}{ Atomic concentration $(\%)$} \\
\cline { 2 - 5 } & $\mathrm{C}$ & $\mathrm{N}$ & $\mathrm{O}$ & $\mathrm{Si}$ \\
\hline 0.2 & 58.8 & 7.3 & 25.2 & 8.7 \\
0.5 & 57.6 & 8.1 & 25.3 & 9.0 \\
1.0 & 58.9 & 7.3 & 25.2 & 8.6 \\
\hline
\end{tabular}

on the copper foil. The immersion time of 1 min appears to be insufficient for the adsorption of $\gamma$-APS. The element ratio becomes almost constant at $\geq 5 \mathrm{~min}$ and is close to the composition of $\gamma$-APS. Thereafter, an immersion time of 5 min is adopted. As shown in Table 2, the effect of the concentration on the element ratio becomes negligible when the concentration is $0.2 \%$ or higher, suggesting that the surface of the copper foil is almost completely covered with $\gamma$-APS. The surface of the copper foil is microscopically irregular [9]. Nevertheless, as long as the element ratio as discussed above is close to that of $\gamma$-APS, it is reasonable to believe that the material on the surface of the copper foil is $\gamma$-APS or its derivatives [1]. Further, we find only a small amount of $\mathrm{Si}(1.8 \%)$ in the case where the immersion process is quickly followed by washing with water and drying, even if the immersion time is $5 \mathrm{~min}$. However, once water is evaporated from the surface by taking more than $10 \mathrm{~h}$, the surface composition does not change as far as we wash it with water at $25^{\circ} \mathrm{C}$. This result suggests that the adsorption rate of the silane coupling agent on the copper foil is considerably slow. It is further expected that $\mathrm{pH}$ affects the adsorption of the silane coupling agent. Aqueous solutions are prepared with $\mathrm{pH}$ values adjusted by using caustic soda or hydrochloric acid. Based on an XPS element analysis of the adsorbed surface, Fig. 2 shows the $\mathrm{pH}$ dependence obtained by assuming that the amount of silicon means the amount of adsorbed $\gamma$-APS. This shows that the amount of $\gamma$-APS is very small under strong acidity or basicity conditions. For the aqueous solution of $\gamma$-APS, where $\gamma$-APS is simply dissolved in water, $\mathrm{pH}$ is about 10 . In this case, the surface silicon content is nearly equal to $9 \%$ and the surface of the copper

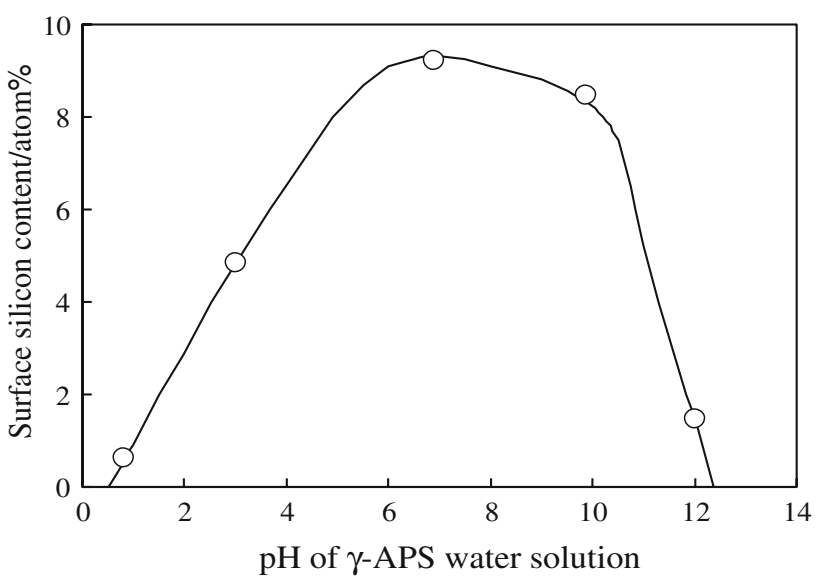

Fig. 2 Surface silicon content as a function of $\mathrm{pH}$ of $\gamma$-APS water solution. Element ratio in which detected all elements are calculated as 100

foil is completely covered with $\gamma$-APS, the content of which is $9.1 \%$.

Structures of adsorbed molecules

If $\gamma$-APS reacts ideally with water molecules by hydrolysis as given by Eq. 1 and is adsorbed on the surface of the copper foil in the form of trisilanol, the element ratio should result in $\mathrm{C} / \mathrm{N}=\mathrm{C} / \mathrm{Si}=3.0$. On the other hand, if molecules are adsorbed without hydrolysis, this should result in $\mathrm{C} / \mathrm{N}=\mathrm{C} / \mathrm{Si}=6.0$, and intermediate values are expected under insufficient hydrolysis conditions. Table 3 shows the effect of the $\gamma$-APS concentration on the element ratio of the copper foil surface. The experimental values are clearly different from three and are close to six in the element ratio $(\mathrm{C} / \mathrm{N}$ and $\mathrm{C} / \mathrm{Si})$. This result clearly indicates that the top surface of the adsorbed material is not composed of the silanol compound as suggested by Eq. 1 . According to Ishida's discussion [4], the top surface is completely covered with physisorbed $\gamma$-APS.
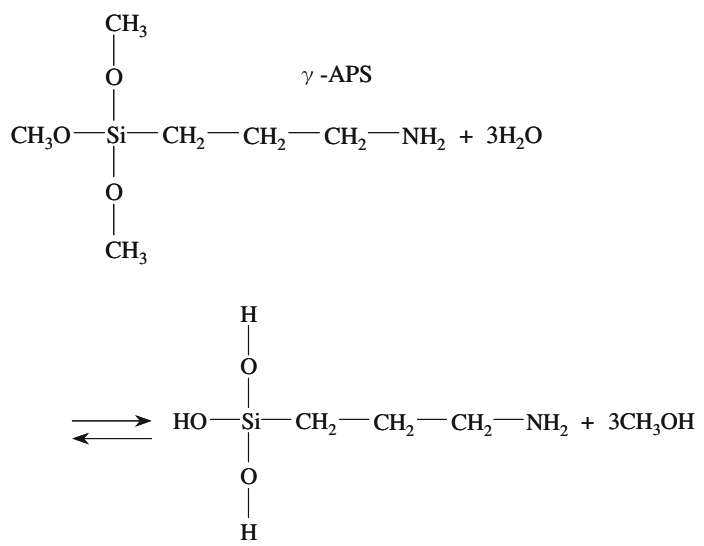
Table 3 Element ratios in adsorbed surface

\begin{tabular}{lll}
\hline $\begin{array}{l}\text { Concentration } \\
\text { of } \gamma \text {-APS }(\%)\end{array}$ & $\mathrm{C} / \mathrm{Si}$ & $\mathrm{C} / \mathrm{N}$ \\
\hline 0.2 & 6.8 & 8.0 \\
0.5 & 6.4 & 7.1 \\
1.0 & 6.8 & 8.1 \\
\hline
\end{tabular}

It is currently known that the XPS analysis of the chemical composition in vertical direction becomes more accurate when $\mathrm{C}_{60}$ fullerene ions with large molecule size are used instead of the popularly used Ar ion since the etching becomes free from contamination [10]. Here, vertical XPS analyses are conducted with $\mathrm{C}_{60}$ fullerene ions for the copper foil immersed in a $1.0 \%$ aqueous solution of $\gamma$-APS. Figure 3 shows the elemental composition on the top surface. Further the depth profile on the element composition is shown in Fig. 4. Metals such as $\mathrm{Ni}$ and $\mathrm{Cr}$ are not found at the top surface, and detected at greater depths of etching. From these results, we can say that the surface is completely covered with the silane coupling agent, and the $\mathrm{C} / \mathrm{N}$ ratio on the top surface is 6.0 . In just below the top surface, it is still close to the element ratio of the silane coupling agent without hydrolysis. Additionally, the silane coupling deposited very much on copper foil in 7 and 10 in $\mathrm{pH}$ as shown in Fig. 2. The $\mathrm{C} / \mathrm{N}$ ratio in this case is also around 6.0. Most of the adsorption layer consists of the silane coupling agent with only partial hydrolysis. Figure 5 shows the vertical distribution for the copper foil

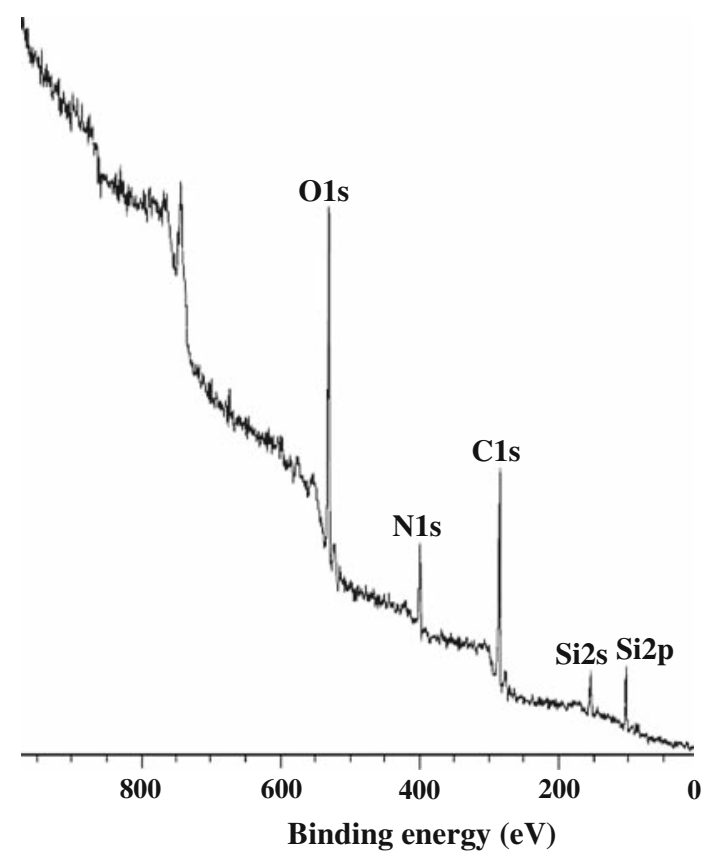

Fig. 3 XPS spectrum of copper foil on which $\gamma$-APS is adsorbed. The foil was immersed in water solution of $\gamma$-APS at $1.0 \%$ (M-1)

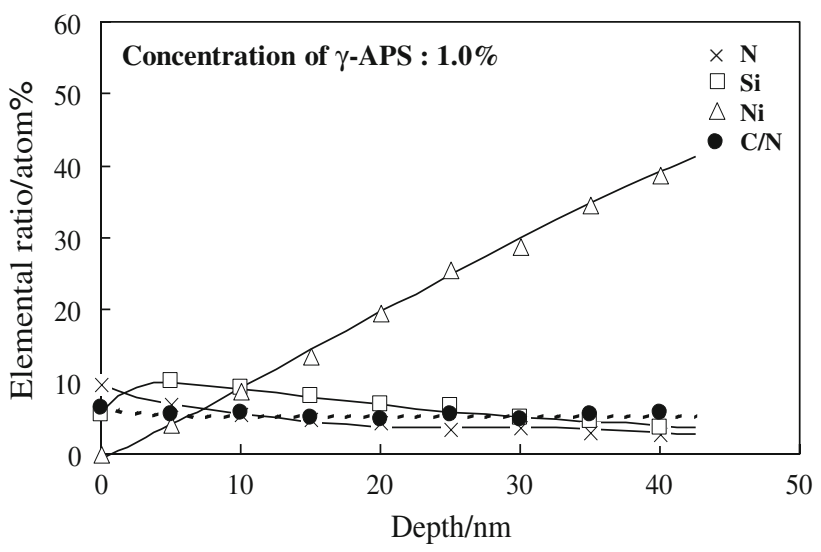

Fig. 4 Depth profiles of some elements and element ratio on copper surface (M-2)

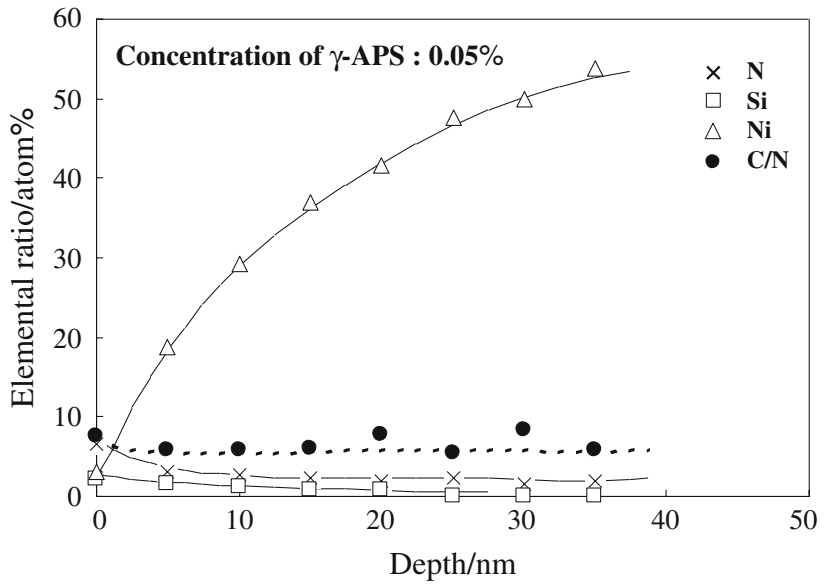

Fig. 5 Depth profiles of some elements and element ratio on copper surface (M-2)

immersed in $0.05 \%$ aqueous solution of $\gamma$-APS. In this case, a small amount of $\mathrm{Ni}$ is observed in the top surface. The value on $\mathrm{Si}$ indicates that there is no silane coupling agent below depths of about $20 \mathrm{~nm}$, suggesting that the adsorption layer is very thin as compared with that in $1.0 \%$ aqueous solution. However, the behavior of $\mathrm{C} / \mathrm{N}$ is almost the same in the case of $1.0 \%$ solution. It is difficult to estimate the interfacial structure between the copper foil and the silane coupling agent solely from the $\mathrm{C} / \mathrm{N}$ value, because the value is influenced by the carbon already present on the surface of the non treated copper foil. In any case, there is no strong evidence of hydrolysis in the large part of the adsorption layer of the silane coupling agent. The concentration of the silane coupling agent gradually increases in the ordinary drying process, and the equilibrium condition shown in Eq. 1 should shift in the direction of hydrolysis when methanol is removed from the solution. It is expected that methanol vaporizes preferentially and is removed from the system since the boiling point of 
methanol is $22^{\circ}$ lower than that of water. However, the above result is different from this expectation. Thus, we tried to generate the silanol compound on the copper foil surface by the following method.

\section{Adsorption layer after freeze dry}

The melting points of water and methanol are very different $\left(0\right.$ and $\left.-97.8^{\circ} \mathrm{C}\right)$. It is considered that methanol can be preferentially removed under reduced pressure if the aqueous solution is frozen while methanol remains liquid. The freeze-dry method is adopted for this purpose. Copper foil is immersed in an aqueous solution of $\gamma$-APS in an eggplant-type flask, and after $2 \mathrm{~h}$ it is frozen in methanol cooled with dry ice. Freeze drying is conducted in this condition to remove water after evaporation of methanol, and XPS analysis of the copper foil surface is carried out. The result is shown in Table 4, where it is clear that the amount of $\mathrm{C}$ is relatively small. This element ratio clearly indicates that the structure is likely to be the one in the right part of Eq. 1, which has an element ratio $\mathrm{C}: \mathrm{N}: \mathrm{O}: \mathrm{Si}=37.5: 12.5: 37.5: 12.5$. This result suggests that methanol is preferentially removed by freeze drying and the adsorption layer is expected to consist of trihydroxysilane.

Consequently, the structure of the deposited or adsorbed layers on the copper foil depends upon the drying method and is estimated to have the structures shown by Fig. 6 . The surface formed by freeze-dry method is expected to have high adhesive strength, because the molecules bond strongly each other by silanol groups. Additionally, the observed molecules might be polymers or strongly adsorbed molecules which have no vapor pressure, since these results are obtained by XPS analysis which is performed in a vacuum of $10^{-6} \mathrm{~Pa}$ or more.

Table 4 Effect of concentration on amount of adsorbed $\gamma$-APS

\begin{tabular}{lllll}
\hline $\begin{array}{l}\text { Concentration } \\
\text { of } \gamma \text {-APS }(\%)\end{array}$ & \multicolumn{4}{l}{ Element ratio $(\%)$} \\
\cline { 2 - 5 } & $\mathrm{C}$ & $\mathrm{N}$ & $\mathrm{O}$ & $\mathrm{Si}$ \\
\hline 1.0 & 44.0 & 12.8 & 29.7 & 13.6 \\
2.0 & 37.3 & 12.6 & 37.0 & 13.1 \\
\hline
\end{tabular}

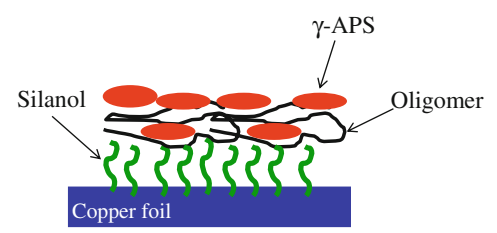

(a)

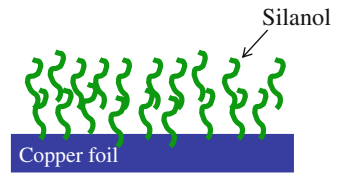

(b)
Fig. 6 Scheme of adsorbed layer. a Water is evaporated at room temperature. b Water is removed by freeze-dry method
Table 5 Element composition of precipitated powder

\begin{tabular}{lllll}
\hline & \multicolumn{4}{l}{ Element ratio (\%) } \\
\cline { 2 - 5 } & $\mathrm{C}$ & $\mathrm{N}$ & $\mathrm{O}$ & $\mathrm{Si}$ \\
\hline Powder 1 & 52.1 & 12.0 & 24.8 & 11.2 \\
Powder 2 & 52.4 & 11.2 & 26.0 & 10.4 \\
Model 1 & 46.1 & 15.4 & 23.0 & 15.4 \\
Model 2 & 50.0 & 12.5 & 25.0 & 12.5 \\
\hline
\end{tabular}

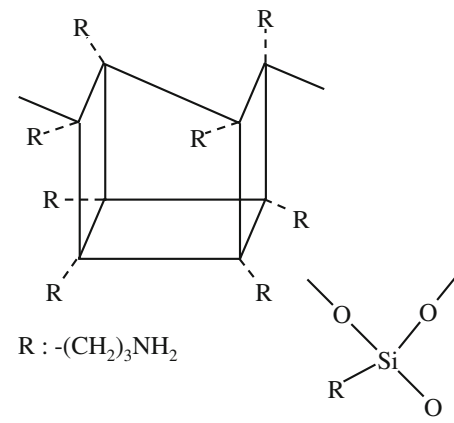

Model 1

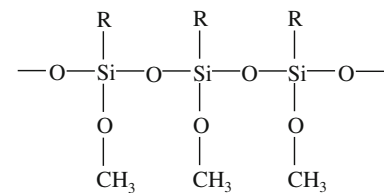

Model 2
Fig. 7 Molecular models for the powder obtained by freeze-dry method

In addition to the above described copper foil, a small amount of white powder is found at the bottom of the flask after the freeze-dry process. The result of the XPS composition analysis for this material is shown in Table 5. The observed elemental composition has a ratio of carbon smaller than $\gamma$-APS, suggesting that the number of methyl groups is reduced and larger molecules are formed. Ishida et al. [4] proposed a molecule model ("Model 1" in Fig. 7) for polymers produced from a silane coupling agent. However, in this model, the portion of carbon is smaller than the experimental values (Powder 1 and 2) by as much as $6 \%$. Furthermore, there are discrepancies also in nitrogen and silicon concentrations. We propose a simpler "Model 2." The result shown in Table 5 agrees fairly well with the elemental composition of the white powder. While the carbon concentration is somewhat small in this model, the results are numerically more consistent if it is assumed that the molecular tails are terminated with a methyl group when molecules are oligomers.

\section{Conclusions}

Copper foil is immersed into an aqueous solution of $\gamma$-APS, in order to investigate the adsorption behavior. The surface is dried in air at room temperature. It is found that the top surface of the adsorbed silane coupling agent consists of 
the agent itself or oligomers of $\gamma$-APS. In addition, the structure of the agent below the top surface does not show signs of hydrolysis. Freeze-drying technique is adopted for removing methanol from $\gamma$-APS aqueous solution containing the copper foil. It is confirmed that the methyl group is removed from the structure of $\gamma$-APS by means of hydrolysis and silanol compound like trihydroxysilane is formed on the copper foil.

Open Access This article is distributed under the terms of the Creative Commons Attribution Noncommercial License which permits any noncommercial use, distribution, and reproduction in any medium, provided the original author(s) and source are credited.

\section{References}

1. Ishida H, Suzuki Y (1986) In: Ishida H, Koenig JL (eds) Composite interfaces, Elsevier, New York, p 317

2. Arkles B, Steinmetz JR, Zazyczny J, Metha BP (1992) In: Mittal KL (ed) Silanes and other coupling agents. VSP, Utrecht, p 91
3. Leyden DE, Atwater JB (1992) In: Mittal KL (ed) Silanes and other coupling agents. VSP, Utrecht, p 143

4. Ishida H (1985) In: Ishida H, Kumar G (eds) Molecular characterization of composite interfaces, Plenum Press, New York, p 25

5. Matinlinne JP, Laajalehto K, Lassile LV, Urpo AY, Vallittu PK (2004) In: Mittal KL (ed) Silanes and other coupling agents, vol 3. VSP, Utrecht, p 21

6. Liu XM, Thomason JL, Jones FR (2009) In: Mittal KL (ed) Silanes and other coupling agents, vol 5. VSP, Utrecht, p 39

7. Miller JD, Ishida H (1984) Surf Sci 148:601

8. Suzuki M (2003) J Surf Sci Soc Jpn 24:222

9. Ogawa T, Baba S, Fujii Y (2006) J Appl Polym Sci 100:3403

10. Nobuta T, Ogawa T (2009) J Mater Sci 44:1800. doi:10.1007/ s10853-009-3274-5 